\title{
Characterization of the $\chi \psi$ subcomplex of Pseudomonas aeruginosa DNA polymerase III
}

\author{
Sirine El Houry Mignan ${ }^{1 \dagger}$, Gregor Witte ${ }^{2,3,4 \dagger}$, Natalie Naue ${ }^{1}$ and Ute Curth ${ }^{1 *}$
}

\begin{abstract}
Background: DNA polymerase III, the main enzyme responsible for bacterial DNA replication, is composed of three sub-assemblies: the polymerase core, the $\beta$-sliding clamp, and the clamp loader. During replication, single-stranded DNA-binding protein (SSB) coats and protects single-stranded DNA (sSDNA) and also interacts with the $\chi \psi$ heterodimer, a sub-complex of the clamp loader. Whereas the $\chi$ subunits of Escherichia coli and Pseudomonas aeruginosa are about $40 \%$ homologous, $P$. aeruginosa $\psi$ is twice as large as its $E$. coli counterpart, and contains additional sequences. It was shown that $P$. aeruginosa $\chi \psi$ together with SSB increases the activity of its cognate clamp loader 25 -fold at low salt. The E. coli clamp loader, however, is insensitive to the addition of its cognate $\chi \psi$ under similar conditions. In order to find out distinguishing properties within $P$. aeruginosa $\chi \psi$ which account for this higher stimulatory effect, we characterized $P$. aeruginosa $\chi \psi$ by a detailed structural and functional comparison with its E. coli counterpart.
\end{abstract}

Results: Using small-angle X-ray scattering, analytical ultracentrifugation, and homology-based modeling, we found the N-terminus of $P$. aeruginosa $\psi$ to be unstructured. Under high salt conditions, the affinity of the $\chi \psi$ complexes from both organisms to their cognate SSB was similar. Under low salt conditions, P. aeruginosa $\chi \psi$, contrary to $E$. coli $\chi \psi$, binds to ssDNA via the $N$-terminus of $\psi$. Whereas it is also able to bind to double-stranded DNA, the affinity is somewhat reduced.

Conclusions: The binding to DNA, otherwise never reported for any other $\psi$ protein, enhances the affinity of $P$. aeruginosa $\chi \psi$ towards the SSB/sSDNA complex and very likely contributes to the higher stimulatory effect of $P$. aeruginosa $\chi \psi$ on the clamp loader. We also observed DNA-binding activity for $P$. putida $\chi \psi$, making this activity most probably a characteristic of the $\psi$ proteins from the Pseudomonadaceae.

\section{Background}

Pseudomonas aeruginosa is a ubiquitous Gram-negative bacterium that causes high rates of hospital-acquired infections, especially in immunocompromised patients [1] as well as in patients with cystic fibrosis [2]. P. aeruginosa infections are often difficult to treat because the pathogen is capable of very rapidly acquiring a multitude of resistance mechanisms [3], making multidrug resistant $P$. aeruginosa strains increasingly common and raising the need for new antipseudomonal drugs. The replication machinery of $P$. aeruginosa presents a good target for the development of new antimicrobial agents,

\footnotetext{
* Correspondence: curth.ute@mh-hannover.de

+ Contributed equally

'Institute for Biophysical Chemistry, Hannover Medical School, Carl-Neuberg-

Str. 1, 30625 Hannover, Germany

Full list of author information is available at the end of the article
}

since DNA replication is essential for the survival of the pathogen.

DNA polymerase III holoenzyme is the main enzyme involved in the replication of the bacterial genome. In Escherichia coli, this multiprotein complex is composed of ten distinct subunits that are arranged into three functional subassemblies [4]. The core subassembly contains the DNA polymerase and the proofreading exonuclease activities [5]. The $\beta$-sliding clamp encircles the DNA duplex while binding to the core and thereby tethering it to the DNA template, ensuring high processivity and speed of the holoenzyme [6]. The clamp loader complex, composed of subunits $\tau / \gamma, \delta, \delta, \chi$ and $\psi$, uses ATP hydrolysis to load the clamp onto DNA [7].

The $\tau / \gamma, \delta$ and $\delta$ ' subunits together form the "minimal" clamp loader, $(\tau / \gamma)_{3} \delta \delta$, which is sufficient for loading the clamp. The $\chi$ and $\psi$ subunits are not essential for clamp

\section{Biomed Central}


loading [8]. However, $\chi$ is the only direct link between DNA polymerase III and SSB, the single-stranded DNAbinding protein $[9,10]$ which coats single-stranded DNA (ssDNA) at the lagging strand to protect it from degradation and to prevent hairpin formation. The $\mathrm{SSB} / \chi$ interaction is necessary for the primase-to-polymerase switch, which involves a competition between DnaG primase and $\chi$ in binding to SSB [11]. The $\psi$ subunit bridges $\chi$ to the $(\tau / \gamma)_{3} \delta \delta$ ' complex and has been shown to play an important role in stabilizing the clamp loader [12] and increasing its affinity for the $\beta$-clamp [13]. In E. coli, $\chi$ and $\psi$ form a tight 1:1 complex, the crystal structure of which has been solved [14]. The residues at the interface between $\chi$ and $\psi$ are highly conserved across several bacterial species [14], and the same holds true for a hydrophobic surface pocket of $\chi$ surrounded by basic residues which was shown to interact with the amphipathic C-terminus of SSB [15]. The disordered Nterminal part of $\psi$ is also well-conserved, and is required for the binding of $\chi \psi$ to the minimal clamp loader [16]. However, in several bacterial genomes containing $\chi$ sequences in which the $\psi$-binding site appears to be conserved, $\psi$ sequences cannot be found, suggesting that $\psi$ has greatly diverged in these species [14].

Sequence comparisons between $E$. coli and $P$. aeruginosa identified the existence of all genes encoding the subunits of DNA polymerase III except for $\theta$, a nonessential subunit of the core, and $\psi$ [17]. The $\psi$ subunit could only be identified as a $32 \mathrm{kDa}$ protein which copurified with the other DNA polymerase III subunits from $P$. aeruginosa cell lysate [18]. The start codon of the gene encoding this subunit was found to be incorrectly annotated in the $P$. aeruginosa PAO1 genome, the actual start codon being a non-canonical UUG present 135 nucleotides upstream from the originally annotated one. Examination of the $\psi$ amino acid sequence showed that it is divergent from and nearly twice the length of E. coli $\psi$. At the functional level, the P. aeruginos $\chi \psi$ complex appears to play a more significant role than its E. coli counterpart. Jarvis et al. [18] observed that, under low salt conditions and at subsaturating levels of the $\tau_{3} \delta \delta$ ' minimal clamp loader, the addition of $P$. aeruginosa $\chi \psi$ and SSB has a synergistic effect, increasing the activity of $P$. aeruginosa $\tau_{3} \delta \delta$ ' 25 -fold. In contrast, under similar conditions, E. coli $\tau_{3} \delta \delta$ ' was insensitive to the addition of E. coli $\chi \psi$ [17]. At high salt concentrations, however, both $\chi \psi$ and SSB are required for efficient DNA synthesis, in the $P$. aeruginosa as well as in the $E$. coli systems [18].

This report describes the biophysical characterization of the $\chi \psi$ complex of $P$. aeruginosa, revealing properties which distinguish it from its $E$. coli counterpart and possibly account for its higher stimulatory effect. Using analytical ultracentrifugation, we show that $P$. aeruginosa $\psi$, but not the E. coli $\psi$ subunit, binds to ssDNA under low salt conditions, even when the ssDNA is coated with SSB. This binding results in an increased affinity of $P$. aeruginosa $\chi \psi$ toward the SSB/ssDNA complex when compared to the $E$. coli system. In addition, we found that P. putida $\chi \psi$ also binds to ssDNA, suggesting that DNA-binding is a property of $\psi$ proteins from the Pseudomonadaceae.

\section{Results and Discussion}

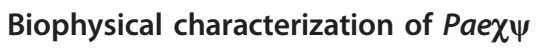

To determine the composition of $P$. aeruginosa $\chi \psi$ $($ Pae $\chi \psi)$, the complex was subjected to sedimentation equilibrium experiments in the analytical ultracentrifuge under high salt conditions. The concentration gradients obtained at three different rotor speeds (see Methods section) and two protein concentrations [5.8 $\mu \mathrm{M}$ (Additional file 1: Figure $\mathbf{S} 1 \boldsymbol{A}$ ) and $23.3 \mu \mathrm{M}$ ] could be globally fitted with a single molar mass of $46( \pm 4) \mathrm{kg} / \mathrm{mol}$. There was no indication of multiple species or aggregation. Since the molar mass of a Pae $\psi \psi$ heterodimer calculated from the amino acid composition is $46.2 \mathrm{~kg} /$ mol, the protein exists as a heterodimer in solution. In comparison, examination of the $\chi \psi$ complex of E. coli $(E c o \chi \psi)$ yielded a molar mass of $31( \pm 4) \mathrm{kg} / \mathrm{mol}$ (Additional file 1: Figure S1 B), confirming the formation of $E \operatorname{co} \chi \psi$ heterodimers (calculated molar mass $31.8 \mathrm{~kg} /$ mol) as reported previously [12].

To characterize its hydrodynamic properties, the Pae $\psi \psi$ heterodimer was examined in sedimentation velocity experiments in the analytical ultracentrifuge under high salt conditions. The data measured at three different protein concentrations were analyzed using the

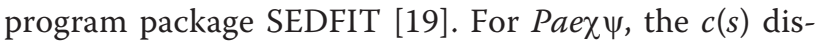
tributions in a concentration range of 1.9 to $15.5 \mu \mathrm{M}$ revealed a single species, sedimenting with an $s_{20}, w$ of $2.5 \mathrm{~S}$, and gave no indication of significant impurities or aggregation products (Additional file 2: Figure S2 $\boldsymbol{A}$ ). Even at the lowest protein concentration used, no change in the $c(s)$ distribution could be observed, showing that the $\chi \psi$ complex is stable under these conditions with no tendency to dissociate. In comparison, the $c(s)$ analysis for $E \operatorname{co} \chi \psi$ resulted in $\mathrm{s}_{20}, \mathrm{w}=2.5 \mathrm{~S}$ and the complex also showed no tendency to aggregate at higher or to dissociate at lower protein concentrations (Additional file 2: Figure S2 B).

From the calculated molar masses of the $\chi \psi$ heterodimers and the measured sedimentation coefficients, the frictional ratios $f / f_{0}$ and the hydrodynamic radii $r_{H}$ were calculated. For the $P$. aeruginosa complex this resulted in $\mathrm{f} / \mathrm{f}_{0}=1.80$ and $\mathrm{r}_{\mathrm{H}}=4.3 \mathrm{~nm}$, whereas the $E$. coli complex yielded $\mathrm{f} / \mathrm{f}_{0}=1.42$ and $\mathrm{r}_{\mathrm{H}}=3.0 \mathrm{~nm}$. Since the frictional ratios for hydrated spherical proteins are expected to be in the range of 1.1 to 1.2 [20], the shape of both 
protein complexes seems to deviate substantially from a sphere. For Eco $\chi \psi$, this is in agreement with the results from the crystal structure [14], where it was shown that the complex is elongated and that the $26 \mathrm{~N}$-terminal amino acids of $\psi$ are disordered. As the frictional ratio of Pae $\psi \psi$ is even larger, a GlobPlot analysis [21] of the $\chi$ and $\psi$ proteins was performed, which predicted the presence of two large disordered regions in the N-termi-

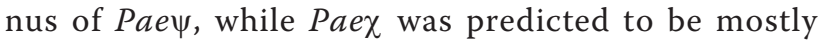
globular (data not shown).

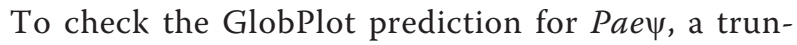
cated version of this protein was constructed in which the $85 \mathrm{~N}$-terminal amino acids were deleted. This con-

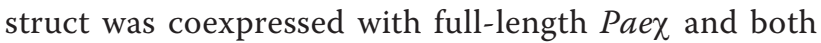
proteins could be copurified as a $\operatorname{Pae\chi } \psi_{(\Delta 1-85)}$ complex. Although the molar mass of this complex was reduced by $9.1 \mathrm{~kg} / \mathrm{mol}$ due to the truncation, it sedimented essentially with the same sedimentation coefficient as observed for full-length Pae $\psi \psi\left(\mathrm{s}_{20}, \mathrm{w}=2.5 \mathrm{~S}\right.$, see additional file 2: Figure S2 C). Accordingly, the frictional ratio and the hydrodynamic radius dropped to $\mathrm{f} / \mathrm{f}_{0}=1.55$ and $\mathrm{r}_{\mathrm{H}}=3.4 \mathrm{~nm}$, respectively. This result makes it very likely that the $\mathrm{N}$-terminal part of Pae $\psi$ is disordered. It is worth noting, however, that the frictional ratio of the truncated complex is still higher than that of Eco $\psi \psi$.

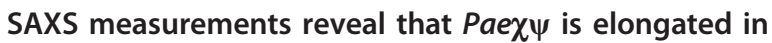 solution}

To get structural information of Pae $\psi$ in solution, and to examine the lack of structure within the $\mathrm{N}$-terminal

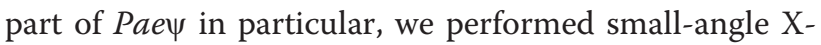
ray scattering (SAXS) experiments of the full-length and the truncated protein complexes (Additional file 3). High-throughput crystallization attempts with both $P a e \chi \psi$ and $P a e \chi \psi(\Delta 1-85)$ unfortunately failed to produce suitable crystals for X-ray crystallography, thus no high resolution structure could be obtained.

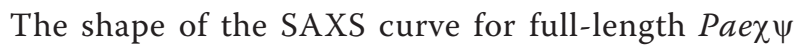
directly suggests an elongated structure of the complex as it resembles a straight line in the lower $\mathrm{s}$ region (Additional file 3: Figure S3 A) [22]. Analysis of the Guinier-plot (log I(s) vs. $\mathrm{s}^{2}$ ) for the lowest protein concentration $(2 \mathrm{mg} / \mathrm{ml})$ yielded a radius of gyration of $R_{G}=$ $4.19 \mathrm{~nm}$. From extrapolation of $\mathrm{I}(\mathrm{s})$ to $\mathrm{s}=0$ and from Porod volume we calculated molar masses of 44.3 and $47.7 \mathrm{~kg} / \mathrm{mol}$, respectively. These observations are in good agreement with the theoretical mass of the Pae $\psi$ heterodimer and with the results of the sedimentation equilibrium experiments. The scattering curves were used to calculate the pair-distribution function, $\mathrm{P}(\mathrm{r})$ (Figure 1A). The plot for the full-length complex is typical of elongated molecules, which are described by functions with a maximum at smaller distances and which usually show tailing at higher distances [23]. The maximum particle diameter, $D_{\max }=14.6 \mathrm{~nm}$, indicates an elongated shape of the $\chi \psi$ heterodimer. The analysis of the scattering data using a Kratky-plot (Additional file 4) suggests that the full-length complex probably contains extensive unfolded regions. A test set of independent $a b$ initio structures, calculated using this dataset, shows large differences among the models and thus supports the idea of a potentially highly flexible part in the complex. To test whether it is the $\mathrm{N}$-terminus of Paew which is unstructured, we performed SAXS experiments with the N-terminally shortened construct Pae $\chi \psi_{(\Delta 1-85)}$. This construct also forms heterodimers $(\mathrm{M}=32 \mathrm{~kg} / \mathrm{mol}$ from $\mathrm{I}(0), \mathrm{M}=33.6 \mathrm{~kg} / \mathrm{mol}$ from Porod volume), but is obviously much more compact and does not possess large protrusions as can be deduced from the $\mathrm{P}(\mathrm{r})$-distribution (Figure $1 \mathrm{~A}$ ) and the value of $\mathrm{R}_{\mathrm{G}}=$ $2.9 \mathrm{~nm}$. These results are also in good agreement with the analytical ultracentrifugation experiments.

We used the sequence of Paew in a semi-automated homology search and modeling approach using the Bioinformatics Toolkit server [24]. The final output model obtained with the program MODELLER [25], using Eco $\psi$ (pdb code: 1em8) as a template, was superimposed on the existing structure of Eco\% [14]. Secondary structure prediction suggests that the Pae $\psi \mathrm{N}$ terminus is potentially unstructured and therefore no structural relatives for this part could be identified. The additional insertions in the core of $\psi$, however, occur in extended or changed loop regions of Eco $\psi$ (Figure 2). These insertions, namely loops II and III, are probably largely unstructured, even though it can not be ruled out that they might fold back and extend the central core $\beta$-sheet. The presence of extended loop structures would be in accordance with the higher frictional ratio of the N-terminally truncated Pae $\psi_{(\Delta 1-85)}$ compared to $E c o \chi \psi$ as measured by analytical ultracentrifugation.

Based on HHpred analysis, the core domains of Pae $\psi$ and $E \operatorname{co} \chi \psi$ show high homologies; we therefore tested whether the $a b$ initio shape calculated from $P a e \chi \psi(\Delta 1-85)$ scattering data is able to harbor the in silico-generated

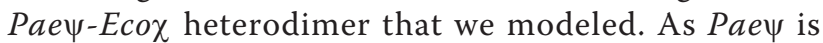
much larger than Eco $\psi$, this model accounts for the putative presence of extended loops in $\mathrm{Pae} \psi$ as predicted from sequence alignment (Figure $2 \mathrm{~A}$ ). The shape of the final $a b$ initio SAXS model of Pae $\chi \psi_{(\Delta 1-85)}$ (Figure $1 C$ ) is clearly able to harbor both the modeled $\chi \psi$-complex and

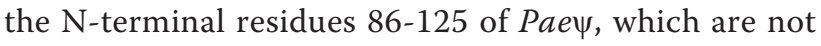
present in our model but in the measured construct.

We further analyzed the SAXS data of the Pae $\psi$ fulllength complex using an alternative approach: lacking data to calculate reliable $a b$ initio models due to the large and probably flexible $\mathrm{N}$-terminus of $\mathrm{Pae} \psi$, we performed an ensemble optimization method approach (EOM) [26]. This procedure creates a large pool of random 


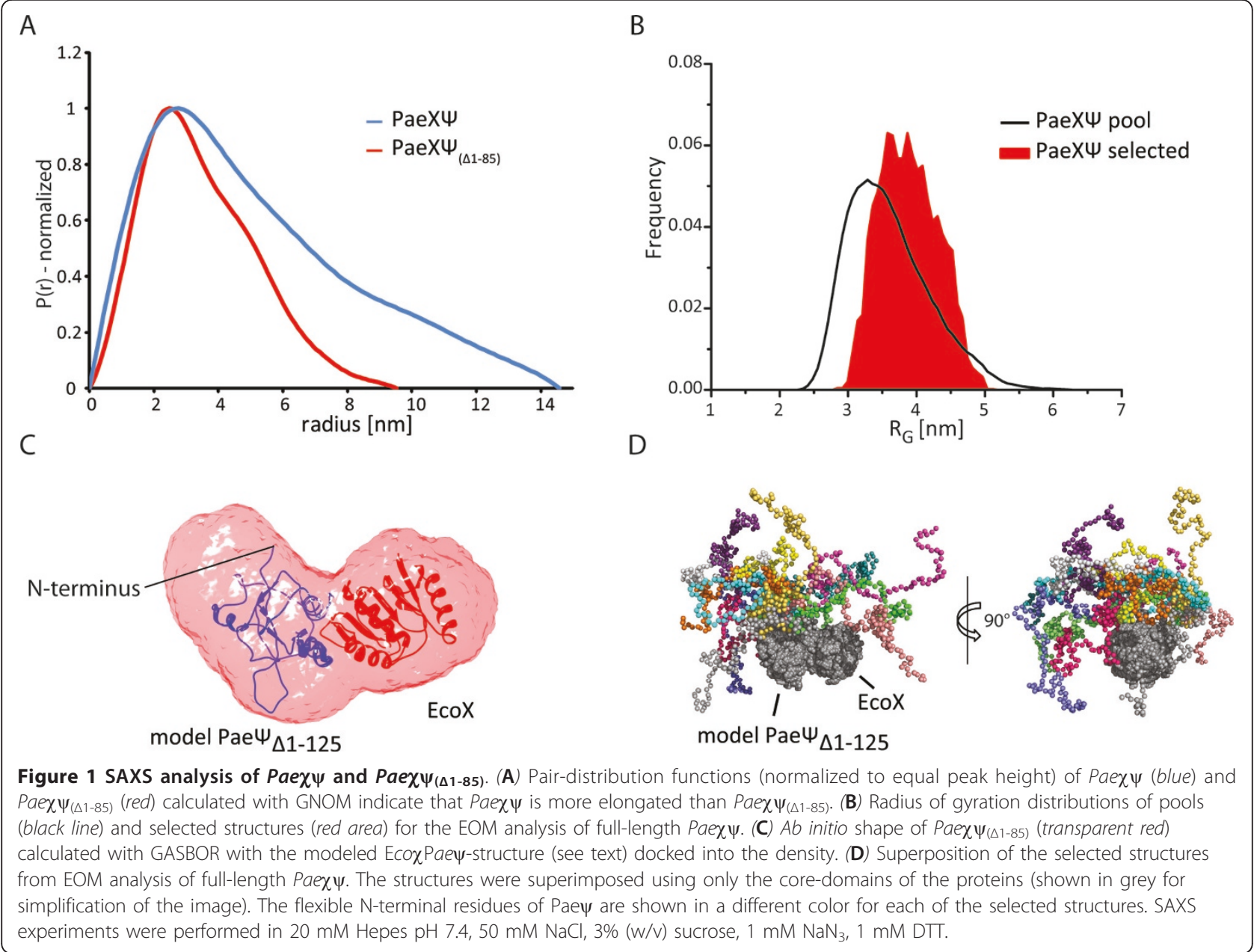

configurations and a genetic algorithm is used to select ensembles being in agreement with the experimental scattering data. For this approach we used our in silicogenerated construct of $\mathrm{Pae} \psi$ and Eco $\chi$ as a rigid (and folded) core and defined the absent N-terminus of Paew as a flexible part containing 125 residues. The $R_{G}$-distribution obtained for the models in the selected ensembles is quite broad (Figure 1B), supporting the idea of high flexibility (e.g. [27]). The chosen ensemble of structures was then superposed (Figure 1D) to visualize the different conformations of the $\mathrm{N}$-terminus which all fit to the measured scattering curve. Additionally, we calculated the theoretical sedimentation coefficients of all structures in the chosen ensemble using HYDROPRO [28]. The average $s$-value of $s_{20}, w=2.6 \pm 0.1 \mathrm{~S}$ is in very good agreement with our experimental data.

\section{Paex $\psi$ binds to the highly conserved C-terminus of SSB}

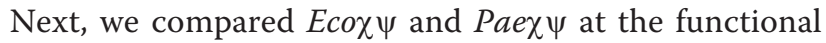
level. Since $E c o \chi \psi$ is known to interact through $\chi$ with the highly conserved C-terminus of EcoSSB, we investigated the interaction between Paex $\psi$ and PaeSSB. When two molecules interact, they form a complex with a larger mass which usually sediments faster than each of the components. Therefore, it is possible to analyze the interaction between $\chi \psi$ and SSB in sedimentation velocity experiments in the analytical ultracentrifuge, as described for the interaction of Eco $\chi$ and Thermus aquaticus SSB [29]. Because free $\chi \psi$ sediments slower than free SSB, Pae $\psi$ was titrated to a constant concentration of PaeSSB in high salt buffer; for comparison, the same experiment was performed with the E. coli proteins. From the $c(s)$ distributions, the concentrations of free $\chi \psi$ were determined, and binding isotherms were constructed using a model for independent binding of $n$ $\chi \psi$ complexes to one SSB tetramer (Figure 3). For the binding of Eco $\psi$ to EcoSSB, we obtained an affinity of $1.8 \times 10^{5} \mathrm{M}^{-1}$, which is in accordance with previously published data on this system [30], and which is within the same range as the binding affinity of only Eco $\chi$ to EcoSSB [10], suggesting that Eco $\psi$ does not play a role in the binding of Eco $\psi$ to SSB. 


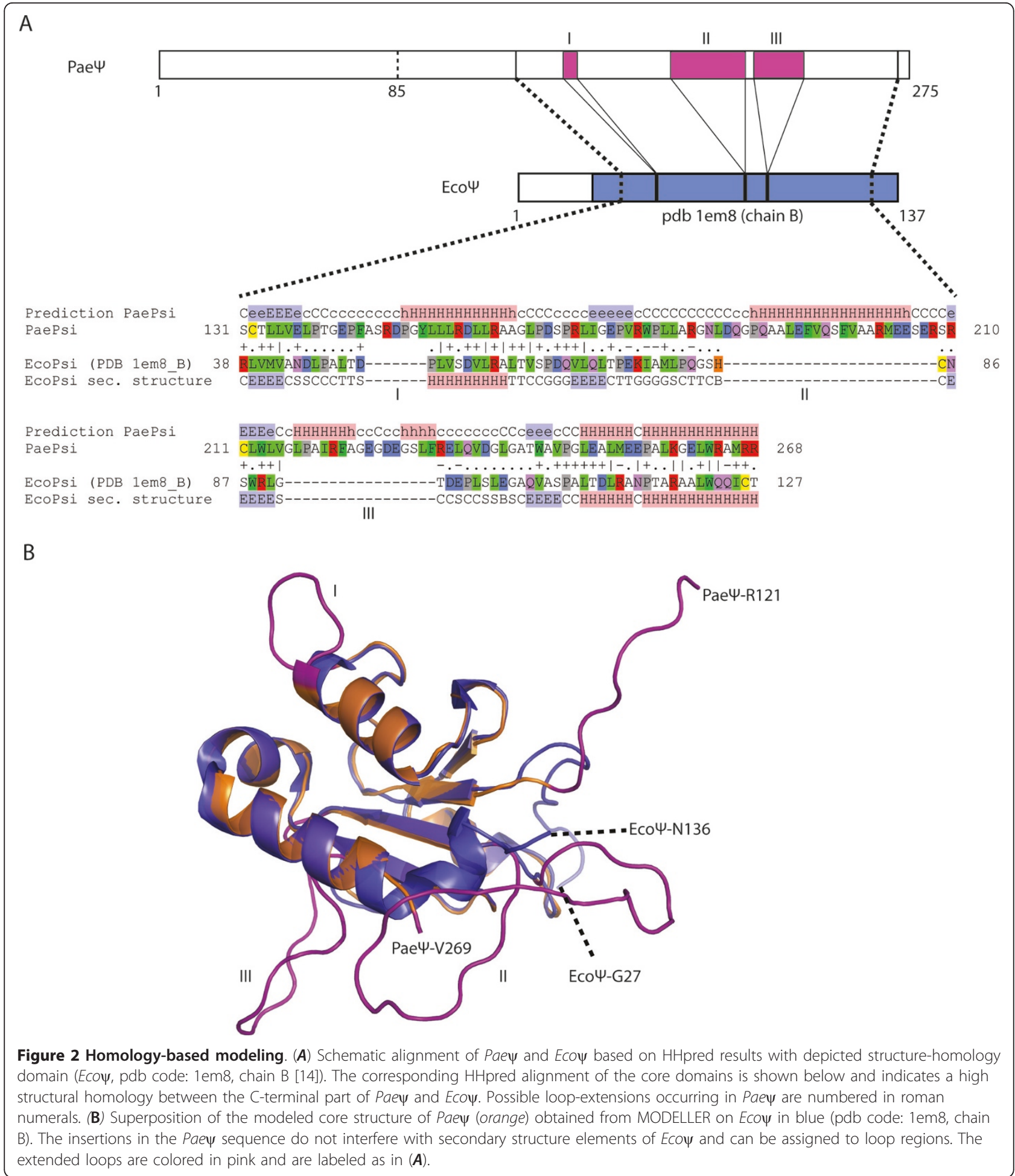

For Paex $\psi$ and PaeSSB, a similar binding affinity of $1.3 \times 10^{5} \mathrm{M}^{-1}$ was obtained under the same experimental conditions (Figure 3). The binding stoichiometry, however, is lower than in the case of E. coli. As both SSB proteins are known to form homotetramers [31,32], there exist four potential binding sites for $\chi \psi$, one at the $\mathrm{C}$-terminus of each monomer. Since the binding isotherm yielded a stoichiometry of $n=3.8$ for the E. coli system, each C-terminus of EcoSSB binds one Eco $\psi$ complex (Figure 3). Correspondingly, it has been shown 


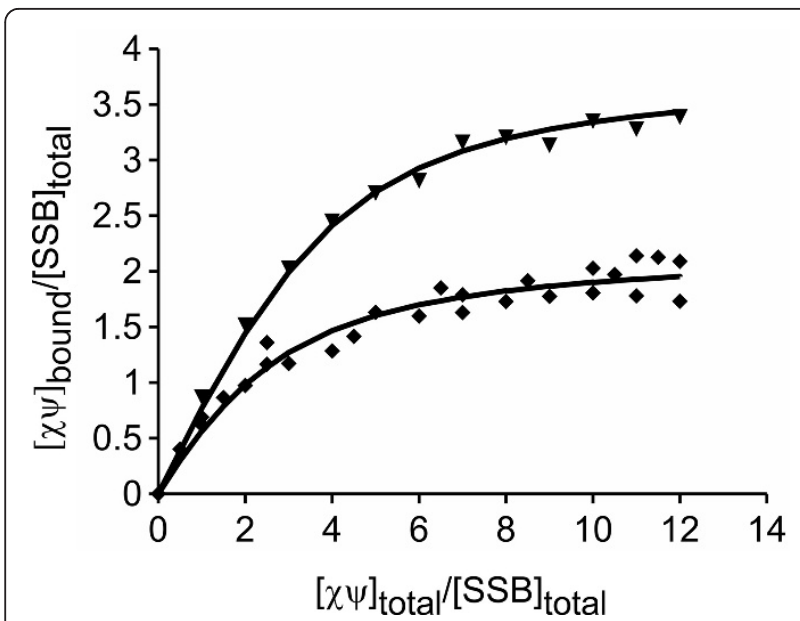

Figure 3 Pae $\psi \psi$ and $E c o \chi \psi$ bind with similar affinities to their cognate SSB proteins. $6 \mu \mathrm{M}$ SSB was sedimented in the analytical ultracentrifuge in high salt buffer, at $50000 \mathrm{rpm}$ and $20^{\circ} \mathrm{C}(\lambda=280$ $\mathrm{nm})$ in the presence of increasing concentrations of $\chi \psi$. Binding isotherms for the interactions of $\chi \psi$ with SSB for the proteins of $P$. aeruginosa (diamonds) and E. coli (triangles) were obtained by analysis of the $c(s)$ distributions (see Methods section). The solid lines represent theoretical binding isotherms calculated for a simple interaction model of $n$ molecules of $\chi \psi$ with one SSB tetramer using the following parameters: Pae $n=2.2, K=1.3 \times 10^{5} \mathrm{M}^{-1}$; Eco $n=3.8, K=1.8 \times 10^{5} \mathrm{M}^{-1}$.

that up to four Eco $\chi$ proteins can bind to EcoSSB [10]. In the case of $P$. aeruginosa, however, not all binding sites can be occupied ( $n=2.2$, Figure 3$)$. This might be due to the fact that Pae $\psi$ is almost twice the size of Eco $\psi$ and that, as was shown above, the N-terminus of Pae $\psi$ is highly elongated. Thus, it is most probably steri-

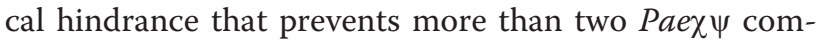
plexes from binding to SSB via $\chi$.

To test whether Pae $\psi \psi$ has the same binding site on SSB as the E. coli complex, we used the deletion mutant EcoSSBQ152* [33], which is truncated of the last 26 amino acids and which has been shown to be unable to interact with Eco [10]. Under high salt conditions, we detected no significant interaction of either

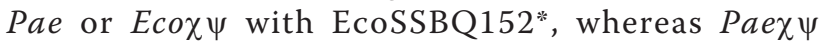
interacted with wild-type EcoSSB with a similar affinity than with PaeSSB (data not shown). Since the $120 \mathrm{~N}$ terminal amino acids of PaeSSB and EcoSSB show 79\% homology and the last 7 amino acids are identical [32], this finding makes it very likely that the highly conserved C-terminus of PaeSSB is the only binding site for Pae $\psi$.

\section{Paew shows DNA-binding activity}

Since the SSB proteins involved in DNA replication form a tight complex with ssDNA, we examined

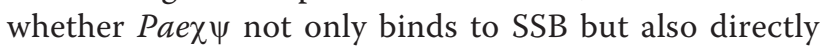
to nucleic acids. We therefore tested the binding of
Pae $\psi$ to fluorescently labeled 50mer-dsDNA and 50mer-ssDNA in electrophoretic mobility shift assays (EMSA) under low salt conditions. Both substrates clearly show shifts with increasing concentrations of Pae $\psi$, indicating binding of the protein complex to the nucleic acids (Additional file 5: Figure S5 $\boldsymbol{A}$ and $\boldsymbol{B}$ ). However, ssDNA is bound with a somewhat higher affinity than dsDNA (Additional file 5: Figure S5 C), suggesting that the complex seems to preferentially bind to ssDNA.

To further characterize the binding to ssDNA substrates, we then performed sedimentation velocity experiments in low salt buffer, titrating Pae or Eco $\chi \psi$ to a constant amount of poly(dT). The binding of the protein to ssDNA was monitored by an increase in the sedimentation coefficient of the latter. Whereas the addition of Eco $\chi \psi$ to poly(dT) did not significantly change the sedimentation coefficient of the ssDNA, addition of Pae $\psi \psi$ resulted in an increase from approximately $4 \mathrm{~S}$ to $24 \mathrm{~S}$, indicating complex formation (Figure 4A). Therefore, in contrast to the E. coli complex, Pae $\chi \psi$ shows binding to ssDNA, which also supports the EMSA results.

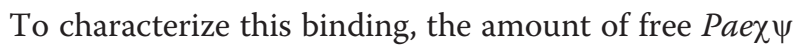
was determined from the $c(s)$ distributions, and a binding isotherm was constructed (Figure 4B). The binding stoichiometry, defined as the amount of $\chi \psi$ bound per $\mathrm{dT}$ residue, was found to be 0.12 . Therefore, one Pae $\psi$ complex is able to bind about eight $\mathrm{dT}$ residues with a binding affinity of approximately $5 \times 10^{5} \mathrm{M}^{-1}$. It is worth noting, however, that the binding affinity of Pae $\chi \psi$ to ssDNA is salt-dependant, since it was weakened at increasing salt concentrations, and no binding was observed in high salt buffer (data not shown). In this context, it is interesting to note that under low salt conditions, but not at elevated salt, ssDNA increases the affinity of Eco $\chi$ to EcoSSB about 20-fold [10]. Under elevated salt conditions, however, in addition to ssDNA, the presence of all other clamp loader subunits, which themselves do not significantly interact with the SSB/ssDNA complex, is required to increase the SSB-binding affinity of Eco $\psi \psi$ about 1000-fold [30]. This might be mediated by a conformational change in the N-terminus of $\psi$ which accompanies the assembly of $\chi \psi$ into the clamp loader complex [16]. A similar conformational change is expected to occur in the conserved ultimate $\mathrm{N}$-terminus of Pae $\psi$, which might also increase the ssDNA-binding

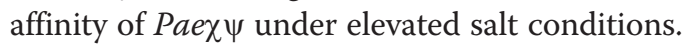

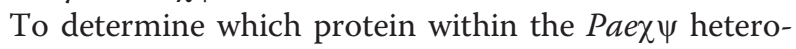
dimer is responsible for ssDNA-binding, we wanted to investigate the interaction of poly(dT) with only Pae $\chi$ or only Pae $\psi$. However, both proteins were insoluble if expressed on their own in E. coli and could not be purified. Therefore, we tried to produce the chimeric 


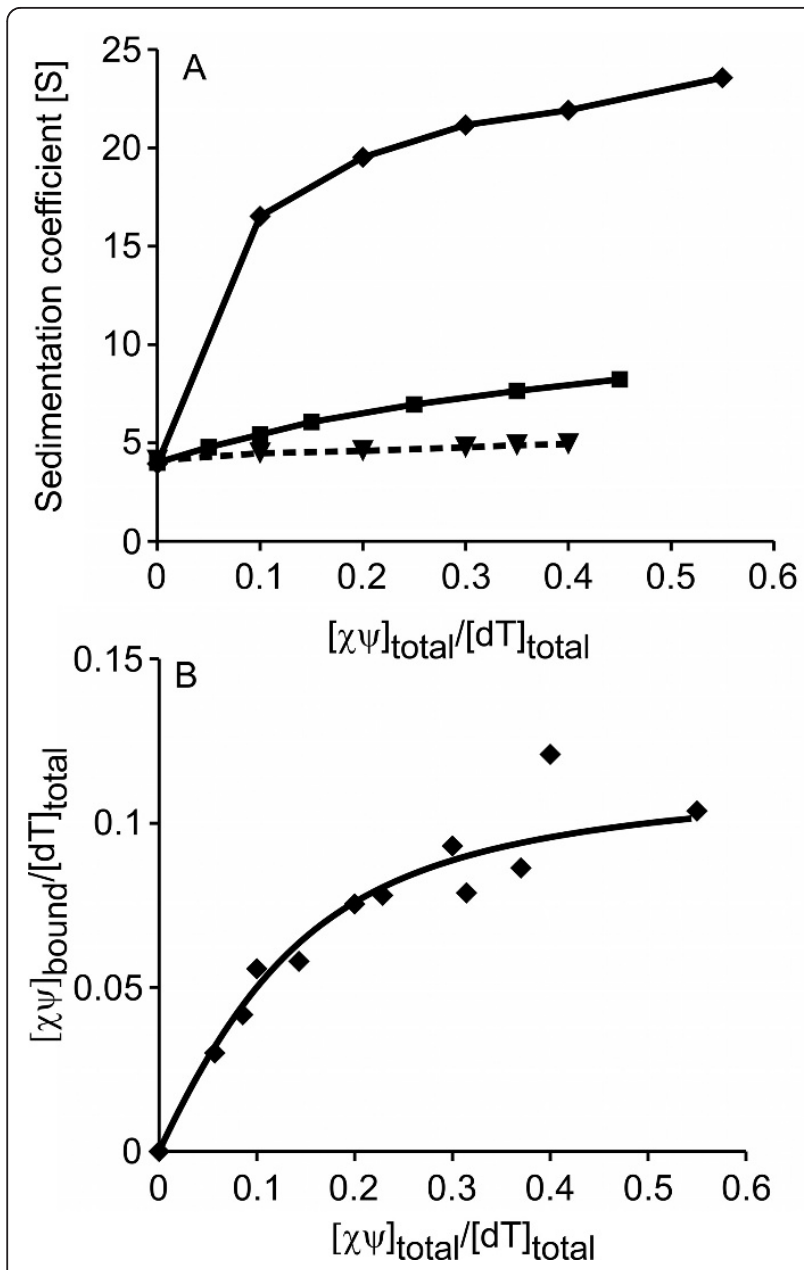

Figure 4 Pae $\chi \psi$ binds to ssDNA. (A) Sedimentation coefficient of $35 \mu \mathrm{M}$ poly(dT) in the presence of Paex $\psi$ (diamonds), Paex $\psi(\Delta 1-85)$ (squares) or Eco $\psi \psi$ (triangles) measured in low salt buffer at $20^{\circ} \mathrm{C}$ and $25000 \mathrm{rpm}(\lambda=280 \mathrm{~nm})$. While the addition of Paex $\psi$ increases the sedimentation coefficient of poly(dT) significantly, indicating the formation of a complex, Ecox $\psi$ shows only a slight effect. The binding of the truncated $P a e \chi \psi_{(\Delta 1-85)}$ is severely reduced compared to wild-type, which shows that the N-terminus of Paew is involved in ssDNA-binding. Lines are drawn just to guide the eye. (B) Binding isotherm for the Paex $\psi /$ poly(dT) interaction, obtained by analysis of the $c(s)$ distributions (see Methods section) of sedimentation velocity experiments at a (dT) concentration of 35 $\mu \mathrm{M}$. The line represents a theoretical binding isotherm calculated for a simple interaction model of $n$ molecules of $\chi \psi$ with one $\mathrm{dT}$ residue using the parameters: $n=0.12$ and $K=5 \times 10^{5} \mathrm{M}^{-1}$.

complexes $\chi_{E c o} \psi_{\text {Pae }}$ and $\chi_{\text {Pae }} \psi_{E c o}$, but only Eco $\chi$ and Pae $\psi$ formed a soluble complex. Although these two proteins are from different organisms, they formed a stable homogeneous heterodimeric $\chi_{E c o} \psi_{\text {Pae }}$ complex as revealed by sedimentation velocity experiments (data not shown). This is most probably due to the fact that the residues at the $\chi \psi$ interface are conserved between

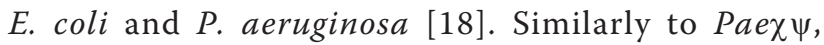
$\chi_{E c o} \psi_{P a e}$ is able to bind to poly $(\mathrm{dT})$ under low salt conditions (Additional file 6). Since we showed that Eco $\psi \psi$ does not bind ssDNA (Figure 4A), and under similar conditions no direct interaction between $E c o \chi$ and ssDNA could be detected $[9,10,30,34]$, it has to be the $\psi$ subunit within Paex $\psi$ which binds to ssDNA.

To check whether the apparently unstructured N-

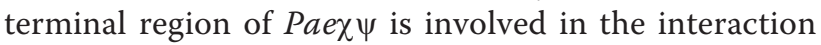
with ssDNA, we tested the binding of the truncated Pae $\chi \psi_{(\Delta 1-85)}$ complex to poly $(\mathrm{dT})$. As can be seen by the smaller increase in the sedimentation coefficient of the

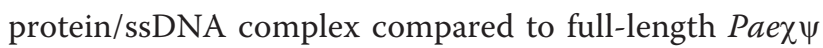
(Figure $4 \mathrm{~A})$, less $\operatorname{Pae\chi } \psi_{(\Delta 1-85)}$ can bind to ssDNA. Therefore, the $\mathrm{N}$-terminal region of $\psi$ is involved in ssDNA-binding.

\section{P. putida $\chi \psi$ also binds to ssDNA}

When the $\psi$ subunit of $P$. aeruginosa was discovered [18], a whole family of $\psi$ proteins present within several species of the Pseudomonadaceae was identified based on sequence comparisons. To test whether ssDNA-binding is a general property of the pseudomonal $\psi$ proteins, we cloned and purified the $\chi \psi$ complex from P. putida. In sedimentation velocity experiments with poly $(\mathrm{dT})$ in low salt buffer, P. putida (Ppu) $\chi \psi$, similarly to Pae $\psi$, increased the sedimentation coefficient of poly(dT), indicating ssDNA-binding (Additional file 6).

\section{Pae $\psi \psi$ binds to ssDNA covered by EcoSSB+Gly}

The ssDNA at the replication fork is entirely covered by SSB $[31,35]$. To have an in vitro setting which most

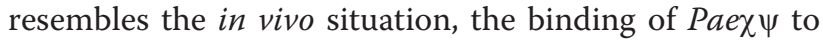
ssDNA complexed with SSB was analyzed. As this experiment is complicated by the fact that $\chi \psi$ also binds to SSB, we used a $\mathrm{C}$-terminal extension mutant of EcoSSB, EcoSSB+Gly. This protein carries an additional glycine residue at its $\mathrm{C}$-terminus which dramatically weakens its interaction with $E c o \chi$ [15]. Using sedimentation velocity experiments, we first confirmed that the binding of both Pae and Eco $\psi$ to this mutant is drastically reduced (Additional file 7 ).

To test whether $\chi \psi$ can interact with ssDNA even when ssDNA is bound by SSB, a saturated complex of $E c o S S B+G l y$ and poly(dT) (35 dT residues per tetramer)

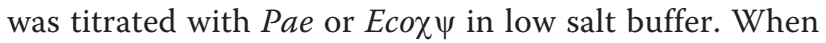
the $E c o S S B+G l y / s s D N A$ complex was analyzed alone, it showed a sedimentation coefficient of approximately $19 \mathrm{~S}$ (Figure 5). The addition of Eco $\psi \psi$ increased the sedimentation coefficient only slightly, to about $21 \mathrm{~S}$, which could be due to a weak binding of Eco $\chi \psi$ to EcoSSB+Gly. The

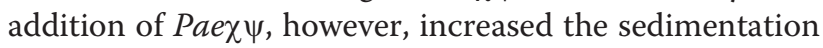
coefficient from approximately $20 \mathrm{~S}$ to $34 \mathrm{~S}$. This clearly shows the formation of a large ternary complex, indicat-

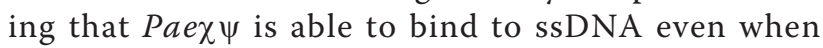
ssDNA is covered by SSB. 


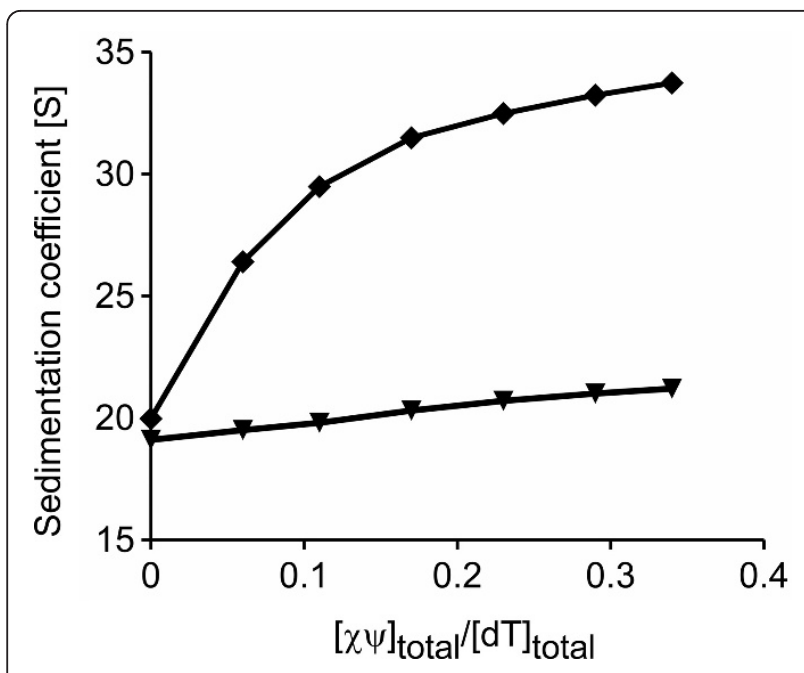

Figure 5 Pae $\psi \psi$ interacts with ssDNA that is covered by

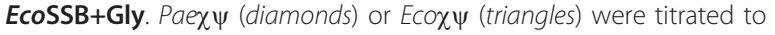
a saturated EcoSSB+Gly/poly(dT) complex containing $1 \mu \mathrm{M}$ SSB and $35 \mu \mathrm{M}$ dT in low salt buffer. The mixtures were sedimented at $22000 \mathrm{rpm}$ and $20^{\circ} \mathrm{C}$, with $\lambda=280 \mathrm{~nm}$. Lines are drawn just to guide the eye. Whereas the addition of $E \operatorname{cox} \psi$ has only a slight effect that might be due to the binding of Eco $\psi \psi$ to EcoSSB+Gly, Paex $\psi$ increases the sedimentation coefficient from $20 \mathrm{~S}$ to about $34 \mathrm{~S}$, indicating that Paex $\psi$ is able to bind to SSDNA even when the latter is saturated with SSB proteins.

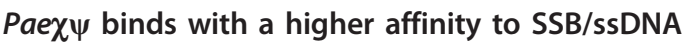 complexes than EcoX $\psi$}

To test whether the ability of Paex $\psi$ to bind both PaeSSB and ssDNA results in an increased affinity toward SSB/ ssDNA complexes, its binding to PaeSSB in the presence or absence of poly(dT) was examined in low salt buffer, and the results were compared to the $E$. coli system. For this purpose, $0.35 \mu \mathrm{M}$ of the respective SSB protein, with or without saturating amounts of poly $(\mathrm{dT})$, were titrated

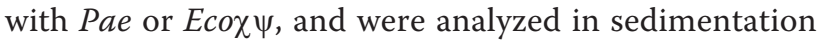
velocity experiments. Figure 6 shows that the binding

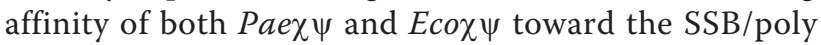
(dT) complex is significantly enhanced compared to the affinity toward free SSB protein, which is consistent with the observation that under low salt conditions, the affinity of Eco $\chi$ to EcoSSB is increased about 20-fold in the presence of ssDNA [10]. This is most probably due to a conformational change of SSB induced by the binding to long stretches of ssDNA, making the highly conserved Cterminal region more easily accessible for interaction with other proteins [36].

In the absence of poly(dT), the binding was too weak to determine the binding parameters for either $P$. aeruginosa or E. coli (Figure 6). Due to the aggregation of Pae $\psi$ at higher protein concentrations at low salt, the binding could not be examined at concentrations which

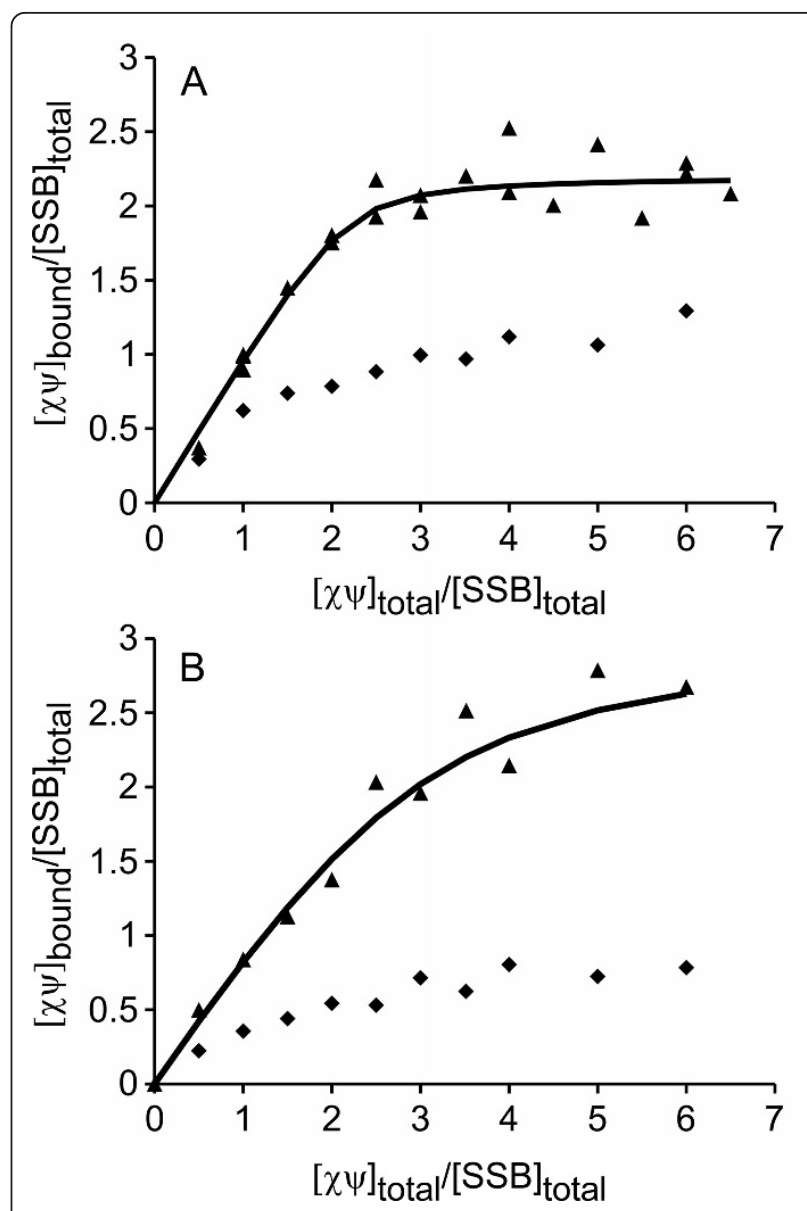

Figure 6 Pae $\psi \psi$ binds to an SSB/ssDNA complex with higher

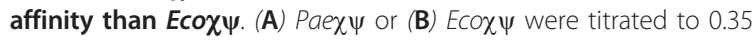
$\mu \mathrm{M}$ of their respective SSB in absence (diamonds) or presence (triangles) of $12.3 \mu \mathrm{M}$ poly(dT), in low salt buffer (50000 rpm or $22000 \mathrm{rpm}$ in the absence or presence of poly(dT), respectively, $20^{\circ}$ $C, \lambda=230 \mathrm{~nm}$ ). The lines represent theoretical binding isotherms calculated for a simple interaction model of $n$ molecules of $\chi \psi$ with one SSB tetramer using the following parameters: (A) $n=2.2$, $K=5 \times 10^{7} \mathrm{M}^{-1}$ and (B) $n=3, K=6 \times 10^{6} \mathrm{M}^{-1}$. The affinity of Paex $\psi$ for the SSB/SSDNA complex is so high that only a lower limit of the binding constant can be given.

would have allowed for the determination of the binding parameters. The binding of Paex $\psi$ to the SSB/ssDNA complex, however, is so strong that even at the lowest concentration that can be applied in AUC experiments using the absorbance optics, stoichiometric binding was observed and the affinity is larger than $5 \times 10^{7} \mathrm{M}^{-1}$ (Figure 6A). Therefore, the affinity of Paex $\psi$ to SSB/poly(dT) is at least eight times higher than the affinity of the respective $E$. coli proteins $\left(\mathrm{K}=6 \times 10^{6} \mathrm{M}^{-1}\right.$, Figure $\left.6 \mathrm{~B}\right)$. This is most probably a result of the ssDNA-binding affinity of Pae $\psi$ which enhances the stability of the ternary complex, when compared to that of the E. coli system. 


\section{Conclusions}

The $\chi$ and $\psi$ subunits are part of the clamp loader of DNA polymerase III holoenzyme. Whereas Eco $\chi$ and Paex have a similar size and show about $40 \%$ sequence homology, Paew is nearly twice as large as its E. coli counterpart. The $\mathrm{N}$-terminal residues of $\psi$ that are needed for the interaction with the minimal clamp loader [16] and the residues involved in binding $\chi$ [14] are conserved, however Pae $\psi$ contains additional sequences that are absent from the E. coli protein. We showed by homology-based modeling that these additional sequences do not interfere with secondary structure elements of Eco $\psi$, but can be assigned to loop regions of the protein (Figure 2B).

Analytical ultracentrifugation experiments revealed

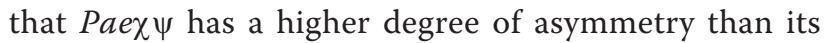
E. coli counterpart. This asymmetry is reduced by the

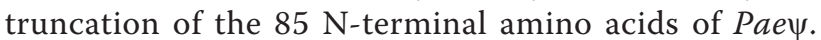
SAXS experiments of Pae $\psi$ and of this truncated variant, as well as molecular modeling, strongly support the idea that the $\mathrm{N}$-terminus of Pae $\psi$ is elongated and probably highly flexible. Our results show that this N-

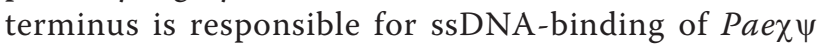
under low salt conditions, a property which can not be

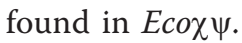

Additionally, we could show that also P. putida $\chi \psi$ is able to bind to ssDNA. To our knowledge, this is the first report on the DNA-binding of $\psi$ subunits of DNA polymerase III. Homology searches within the Pseudomonadaceae revealed several proteins related to $P a e \psi$, all containing extra sequences absent from Eco\%, which were in many cases highly conserved [18]. One conserved region is located in the unstructured $\mathrm{N}$-terminus of $\psi$, includes several positively charged amino acids and might be responsible for the binding of the pseudomonal $\psi$ proteins to DNA (Additional file 8).

Using an EcoSSB mutant impaired in $\chi \psi$ binding, we

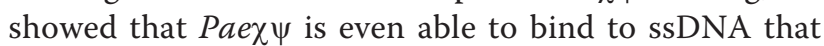
is covered with SSB. Furthermore, we demonstrated that

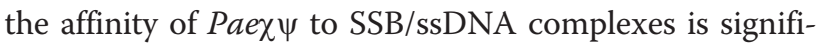
cantly increased compared to the E. coli system. This fact is most probably due to the ability of Pae $\psi$ to bind to ssDNA. It has been shown that under low salt conditions only Pae $\psi \psi$ has a significant influence on DNA synthesis by its cognate DNA polymerase III $[17,18]$. The addition of Paex $\psi$ and SSB shows a synergistic effect, increasing the activity of the minimal clamp loader $P a e \tau_{3} \delta \delta^{\prime} 25$-fold, whereas $E c o \tau_{3} \delta \delta^{\prime}$ is insensitive to the addition of $E c o \chi \psi[17,18]$. Even though it might not be the only mechanism, the binding of Paew to DNA very likely contributes to the higher stimulatory effect of Paex $\psi$ on the minimal clamp loader in the presence of SSB. Since we showed that the $\chi \psi$ complex of $P$. putida is also able to bind DNA, this stimulatory effect might be a characteristic of pseudomonal $\chi \psi$ complexes.

In spite of the fundamental aspects of this work, the full understanding of the DNA polymerase III holoenzyme of $P$. aeruginosa, and of its $\psi$ subunit in particular, may reveal new targets for the development of specific inhibitors of pseudomonal DNA replication. The most striking difference between the E. coli and pseudomonal $\chi \psi$ complexes identified in this work is the ssDNAbinding ability mediated by the $\mathrm{N}$-terminus of Pae $\psi$. Since we showed that this region is unstructured, it can probably not be used directly in antipseudomonal drug design. However, it is tempting to speculate that this region might fold upon ssDNA-binding and one of our

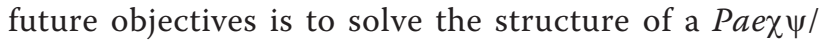
ssDNA complex.

\section{Methods}

\section{Buffers and reagents}

Poly(dT) ( 1400 nt in length) was purchased from GE Healthcare Life Sciences. Its concentration is given in monomer residues throughout the text and was determined spectrophotometrically, using an absorption coefficient of $8600 \mathrm{M}^{-1} \mathrm{~cm}^{-1}$ at maximum [37]. Protein concentrations were determined spectrophotometrically, using the absorption coefficients at $280 \mathrm{~nm}$ calculated from amino acid composition [38]: PaeSSB: $95800 \mathrm{M}^{-1}$

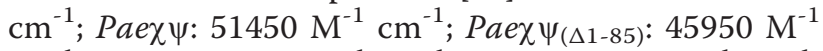

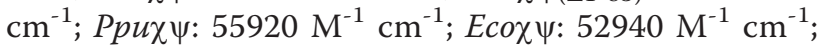
chimeric $\chi_{E c o} \psi_{\text {Pae }}: 63940 \mathrm{M}^{-1} \mathrm{~cm}^{-1}$. For wild-type $E \operatorname{coSSB}$ and EcoSSB+Gly an absorption coefficient of $113000 \mathrm{M}^{-1} \mathrm{~cm}^{-1}$ was used [39].

Experiments were carried out in potassium phosphate buffer $\left(\mathrm{KP}_{\mathrm{i}}\right) \mathrm{pH} 7.4$, containing two different $\mathrm{NaCl}$ concentrations: high salt buffer $\left(0.3 \mathrm{M} \mathrm{NaCl}, 20 \mathrm{mM} \mathrm{KP_{i }}\right.$ $\mathrm{pH}$ 7.4, $0.5 \mathrm{mM}$ DTT), and low salt buffer $(5 \mathrm{mM} \mathrm{NaCl}$, $5 \mathrm{mM} \mathrm{KP}$ i pH 7.4, 0.87 M glycerol, 0.5 mM DTT).

\section{Cloning of the $\chi$ and $\psi$ genes of $P$. aeruginosa, E. coli, and P. putida}

Primer sequences are given in additional file 9. The holC and holD genes of $P$. aeruginosa were amplified by PCR from genomic DNA of strain PAO1. For the holD gene, the start codon was at the position identified in [18]. After BsaI/BamHI digestion, the holC PCR product was cloned into pCDFDuet-1 (Novagen), cut with NcoI/ BamHI. The holD PCR product was cut with BglII/ EcoRI and cloned into the pGEX-6P-1 vector (GE Healthcare Life Sciences), digested with BamHI/EcoRI.

The holC and holD genes of E. coli were amplified by PCR from genomic DNA of E. coli strain LK111ג [40]. The holC PCR product was cut with NcoI/XhoI, and cloned into pET-15b (Novagen), cut with the same enzymes. This construct was then digested with XhoI, 
and the holD PCR product, cut with XhoI, was ligated in.

For expression of the chimeric $\chi_{E c o} \psi_{\text {Pae }}$ complex, the holC gene was amplified by PCR from genomic DNA of

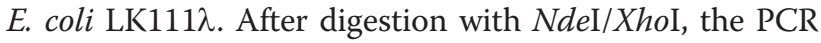
product was cloned into the vector pCDFDuet-1.

The holC and holD genes of P. putida were amplified by PCR from genomic DNA of P. putida strain KT2440 [41] and were cloned into the vectors pRSFDuet-1 (Novagen) and pETGEX-6P, respectively. To construct the latter, the sequence coding for GST and the multiple cloning site were amplified from pGEX-6P-1, and were cloned into $\mathrm{pET}-15 \mathrm{~b}$. In the resulting vector, protein expression is under control of the T7lac promoter and is therefore more tightly regulated than in pGEX-6P-1. For the holD gene, the start codon was at the position identified in [18]. After digestion with $B s a \mathrm{I} / \mathrm{BamHI}$, the holC PCR product was cloned into pRSFDuet-1, cut with NcoI/BamHI. The holD PCR product was cut with $B a m H I / X h o I$ and ligated into pETGEX-6P.

All constructs were checked for errors by sequencing the complete genes (GATC Biotech).

\section{Construction of the $\mathrm{N}$-terminally truncated mutant

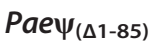

A 582 bp fragment, encoding Pae $\psi$ truncated of its first 85 amino acids $\left(\operatorname{Pae}_{(\Delta 1-85)}\right)$, was amplified by PCR from the genomic DNA of $P$. aeruginosa strain PAO1 (for sequence of primers see additional file 9). After digestion with $B g l \mathrm{II} / E c o$ RI, the PCR fragment was cloned into pGEX-6P-1, cut with BamHI/EcoRI, allowing for the expression of N-terminally GST-tagged $\operatorname{Pae} \psi_{(\Delta 1-85)}$.

\section{Protein expression and purification}

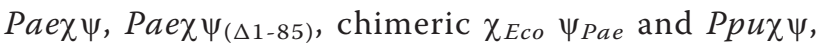
were expressed as $\chi / G S T \psi$. During the purification procedure the GST moiety was cleaved off by PreScission ${ }^{\mathrm{TM}}$ protease digestion. Eco $\chi \psi$ was expressed untagged. Expression of the $\chi$ proteins was done using Duet vec-

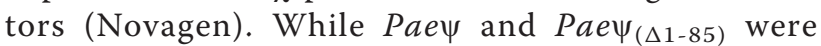
expressed using pGEX-6P-1, Ppu $\psi$ was expressed from pETGEX-6P.

E. coli Rosetta (DE3) pLyS cells (Novagen) were transformed with the respective vectors encoding $\chi$ and GST $\psi$ proteins and were grown to $\mathrm{E}_{600 \mathrm{~nm}}=1.2$ in a 10 $\mathrm{L}$ fermentor flask at $37^{\circ} \mathrm{C}$ in LB medium. $5 \mathrm{~h}$ after addition of $1 \mathrm{mM}$ IPTG cells were harvested, resuspended in an equal volume of PBS (300 $\mathrm{mM} \mathrm{NaCl}, 2.7 \mathrm{mM}$ $\mathrm{KCl}, 10 \mathrm{mM} \mathrm{Na} \mathrm{HPO}_{4}, 1.8 \mathrm{mM} \mathrm{KH_{2 }} \mathrm{PO}_{4}, 10 \%$ (v/v) glycerol, $1 \mathrm{mM}$ DTT, pH 7.3) and frozen in $\mathrm{N}_{2}$ (liq). $40 \mathrm{~g}$ of frozen cells were thawed in the presence of two volumes of PBS buffer, $1 \mathrm{mM}$ EDTA, $1.67 \mathrm{mM}$ DTT, $0.1 \mathrm{mM}$ PMSF, and 10 tablets of complete EDTA-free protease inhibitor (Roche). The suspension was incubated for $20 \mathrm{~min}$ at $4^{\circ} \mathrm{C}$ with $0.3 \mathrm{mg} / \mathrm{mL}$ lysozyme, followed by sonification. After centrifugation, the supernatant was applied onto a glutathione sepharose 4B (GE Healthcare Life Sciences) column preequilibrated with PBS buffer. After washing with GS buffer (50 mM Tris- $\mathrm{HCl} \mathrm{pH} 7.0,150 \mathrm{mM} \mathrm{NaCl}, 10 \%$ glycerol (v/v), $1 \mathrm{mM}$ EDTA, $1 \mathrm{mM}$ DTT), the column was incubated overnight at $4^{\circ} \mathrm{C}$ with $840 \mu \mathrm{g}$ of PreScission ${ }^{\mathrm{TM}}$ protease (GE Healthcare Life Sciences). The $\chi$ and $\psi$ proteins were eluted using GS300 buffer (GS buffer with $0.3 \mathrm{M} \mathrm{NaCl}$ ). Fractions containing the purest complex were pooled and the proteins were precipitated for $1 \mathrm{~h}$ with $164 \mathrm{~g} / \mathrm{L}\left(\mathrm{NH}_{4}\right)_{2} \mathrm{SO}_{4}$ (except for Pae $\psi_{(\Delta 1-85)}$ where $300 \mathrm{~g} / \mathrm{L}$ were used). After centrifugation, the precipitated proteins were resuspended in GS300 buffer and subjected to size exclusion chromatography (Superdex75-prepgrade, GE Healthcare Life Sciences) in the same buffer. Fractions that contained contamination-free $\chi \psi$ complex were pooled, dialyzed overnight against high salt buffer containing $10 \%(\mathrm{v} / \mathrm{v})$ glycerol, flash frozen in $\mathrm{N}_{2}$ (liq) and stored at $-80^{\circ} \mathrm{C}$.

Expression of the Eco $\psi \psi$ complex was done using the pET-15b vector (Novagen). For purification, cells harvested from the fermentor culture were resuspended in $50 \mathrm{mM}$ Tris- $\mathrm{HCl} \mathrm{pH} \mathrm{7.5,} \mathrm{10 \%} \mathrm{(w/v)} \mathrm{sucrose} \mathrm{and} \mathrm{frozen}$ in $\mathrm{N}_{2}$ (liq). $30 \mathrm{~g}$ of frozen cells were thawed in the presence of $0.1 \mathrm{mM}$ PMSF and cell lysis was done as above, but using $0.1 \mathrm{mg} / \mathrm{mL}$ lysozyme. After centrifugation, the proteins in the supernatant were precipitated with $250 \mathrm{~g} / \mathrm{L}\left(\mathrm{NH}_{4}\right)_{2} \mathrm{SO}_{4}$ at $4^{\circ} \mathrm{C}$. The protein pellet after centrifugation was resuspended in buffer A20 (50 mM Tris pH 7.8, 20 mM NaCl, 10\% (v/v) glycerol, $1 \mathrm{mM}$ EDTA, $1 \mathrm{mM}$ DTT), and dialyzed against the same buffer. The solution was applied onto a Qsepharose fast flow (GE Healthcare Life Sciences) column preequilibrated in the same buffer. After washing with buffer A20, the proteins were eluted in a gradient of $20 \mathrm{mM}$ to $250 \mathrm{mM} \mathrm{NaCl}$ in buffer A20. The fractions containing Eco $\chi$ and $\psi$ were pooled and the protein complex was precipitated with $300 \mathrm{~g} / \mathrm{L}$ of $\left(\mathrm{NH}_{4}\right)_{2} \mathrm{SO}_{4}$ at $4^{\circ} \mathrm{C}$. Following centrifugation, the protein pellet was resuspended in buffer A50 (A20 with $50 \mathrm{mM} \mathrm{NaCl}$ ) and applied onto a size exclusion chromatography column (see above) preequilibrated with the same buffer. Fractions containing a contaminationfree $\chi \psi$ complex were pooled and dialyzed overnight against $20 \mathrm{mM}$ Hepes pH 8.0, $100 \mathrm{mM} \mathrm{NaCl}, 2 \mathrm{mM}$ DTT, $1 \mathrm{mM} \mathrm{NaN}_{3}$, and $3 \%(\mathrm{w} / \mathrm{v})$ sucrose, flash frozen in $\mathrm{N}_{2}$ (liq), and stored at $-80^{\circ} \mathrm{C}$.

Expression and purification of EcoSSB and EcoSSB + Gly was performed as described previously [15]. EcoSSB Q152* [33] and PaeSSB [32] were expressed and prepared as described earlier. 


\section{Analytical ultracentrifugation}

Analytical ultracentrifugation experiments were performed either in a Beckman Optima XL-A ultracentrifuge or a Beckman/Coulter ProteomeLab XL-I ultracentrifuge, using An-50 Ti rotors. Concentration profiles were measured with the UV-absorption scanning optics of the centrifuge.

Sedimentation velocity experiments were carried out at $20^{\circ} \mathrm{C}$ in either $12 \mathrm{~mm}$ or $3 \mathrm{~mm}$ standard double-sector centerpieces filled with $400 \mu \mathrm{L}$ or $100 \mu \mathrm{L}$ sample, respectively, at the indicated rotor speeds. For the analysis of protein-protein or protein-DNA interactions, the slower sedimenting molecule was titrated to a constant concentration of the faster sedimenting one. Since the reactions governing the interactions examined in this study are fast compared to the timescale of sedimentation, only two sedimenting boundaries are observed [42]. The slow one represents the free slower sedimenting molecule, whereas the fast one contains complexes of both components and free faster sedimenting molecules.

The measured concentration profiles were evaluated using SEDFIT [19] which transforms them into diffusion-corrected sedimentation coefficient distributions $[c(s)$ distributions]. As the areas under the separate peaks in the $c(s)$ distributions are a measure of the absorbance of the species represented by the peaks [42], this information can be used to determine binding isotherms [29], which were evaluated using a simple interaction model as described previously [10].

In the case of the $\chi \psi / \mathrm{SSB} / \operatorname{poly}(\mathrm{dT})$ experiments where a wavelength of $230 \mathrm{~nm}$ was used, the extinction coefficients of $\chi \psi$ and the SSB/poly(dT) complexes were determined from the observed absorbances in the centrifuge and the known initial concentrations of the components. Thus, it was possible to correct for variations in the exact wavelength provided by the monochromator of the centrifuge.

For hydrodynamic analysis, measured s-values were corrected to $s_{20}$, w, using the partial specific volumes calculated from amino acid composition [43]. Since the partial specific volume of complexes of different macromolecules with unknown composition can not be calculated, uncorrected sedimentation coefficients are given in these cases.

Sedimentation equilibrium experiments were carried out at $4^{\circ} \mathrm{C}$ in either $12 \mathrm{~mm}$ or $3 \mathrm{~mm}$ double-sector centerpieces filled with $150 \mu \mathrm{L}$ or $40 \mu \mathrm{L}$ sample, respectively. Absorbance was detected at $280 \mathrm{~nm}$ and rotor speeds of 9000, 13000 and $18000 \mathrm{rpm}$ were used. Analysis of the data was performed as described earlier [44].

\section{SAXS measurements and modeling of Paew}

Sample preparation for SAXS included dialysis in 20 $\mathrm{mM}$ Hepes pH 7.4, $50 \mathrm{mM} \mathrm{NaCl}, 3 \%(\mathrm{w} / \mathrm{v})$ sucrose, 1
$\mathrm{mM} \mathrm{NaN}, 1 \mathrm{mM} \mathrm{DTT}$, followed by protein concentration using Vivaspin centrifugal concentrators (Sartorius Stedim Biotech). The flowthrough was taken as buffer reference in SAXS data collection. SAXS data were collected at EMBL/DESY X33 beamline (Hamburg, Germany) at $20^{\circ} \mathrm{C}$ cell temperature. Molar mass of the samples was determined by comparison of scattering intensity at zero angle $\mathrm{I}(0)$ obtained from Guinier analysis $\left(\mathrm{s}^{*} \mathrm{R}_{\mathrm{G}}<1.3\right.$ in $\ln (\mathrm{I})$ vs. $\mathrm{s}^{2}$-plot) with reference proteins BSA and lysozyme, and was additionally determined from volume (Porod volume, see e.g. [23]).

SAXS data were processed and analyzed using the ATSAS package [45]. Pae $\psi$ and $P a e \chi \psi_{(\Delta 1-85)}$ were measured at protein concentrations of 2,4 and $8 \mathrm{mg} / \mathrm{ml}$ and $1.3,3.2$ and $6.4 \mathrm{mg} / \mathrm{ml}$, respectively. All sample scattering curves were corrected by subtraction of the corresponding buffer scattering curves. Scattering curves were merged as described in e.g. [23] to obtain optimal data quality at lower and higher s-ranges. For full-length Pae $\psi$, a flexible modeling approach was performed, using the ensemble optimization method (EOM) described in e.g. $[26,27]$. For the truncated Paex $\psi_{(\Delta 1-85)}$ construct, an independent set of ten ab initio bead models was calculated with GASBOR without prior symmetry information or other restrictions. Models were aligned and averaged using DAMAVER. For better representation, an electron density envelope of the averaged bead model was calculated using the SITUS package [46]. SAXS-shape representation and docking into the SAXS shape were performed with the UCSF chimera package [47] and the superposition of structures was done using PyMOL [48].

Modeling of the Pae $\psi$ molecule was performed using

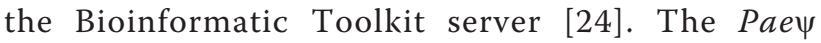
sequence was first analyzed by HHpred [49], identifying Eco\% (pdb code: 1em8) as one of the best candidates with highest score (probability 96.66, E-value $=0.02$, Identities $21 \%$ ). This structure was then chosen as a template for MODELLER [25].

\section{Electrophoretic mobility shift assays (EMSA)}

EMSA was performed in 5\% polyacrylamide gels in Trisborate buffer (running buffer: $45 \mathrm{mM}$ Tris, $45 \mathrm{mM}$ boric acid; gels: $25 \mathrm{mM}$ Tris, $25 \mathrm{mM}$ boric acid) using fluorescently FAM- labeled oligonucleotides (Thermo Fischer). Gels were analyzed using a Typhoon Scanner (488 nm laser, GE Healthcare Life Sciences), and quantified using the ImageQuant software (GE Healthcare Life Sciences). $1 \mu \mathrm{l}$ of DNA was added to the protein in $9 \mu \mathrm{l}$ low salt buffer to yield the indicated final concentrations. The mixture was incubated for $10 \mathrm{~min}$ at room temperature prior to gel electrophoresis at $5^{\circ} \mathrm{C}$. Double-stranded DNA was prepared by annealing of oligonucleotides A and B; oligonucleotide A was used as the ssDNA sample 


\section{(A: 5'6FAM-GGATACGTAACAACGCTTATGCATCG CCGCCGCTACATCCCTGAGCTGAC 3'. B: 5'GTCAG CTCAGGGATGTAGCGGCGGCGATGCATAAGCGT TGTTACGTATCC 3').}

\section{Conflict of interests statement}

The authors declare that they have no competing interests.

\section{Additional material}

Additional file 1: Figure S1. Sedimentation equilibrium concentration

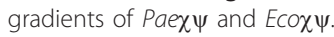

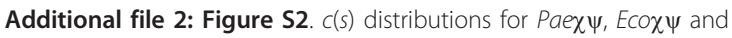
PaeX $\psi_{(\Delta 1-85)}$.

Additional file 3: Figure S3. SAXS data of Paex $\psi$ and $\operatorname{Pae\chi } \psi(\Delta 1-85)$. Additional file 4: Figure S4. Kratky-plot (I. $s^{2}$ vs. s) of the full-length Paex $\psi$ and the truncated form Paex $\psi_{(\Delta 1-85)}$ scattering data.

Additional file 5: Figure S5. Electrophoretic mobility shift assays of Paex $\psi$ with fluorescently labeled ssDNA and dsDNA.

Additional file 6: Figure S6. The chimeric complex $\chi_{E c o} \psi_{P a e}$ and PpuX $\psi$ interact with ssDNA.

Additional file 7: Figure S7. The binding of $\chi \psi$ to the C-terminal extension mutant EcoSSB+Gly is severely reduced.

Additional file 8: Figure S8. Sequence alignment of $\psi$ proteins from different members of the Pseudomonadaceae.

Additional file 9: Primer sequences used for cloning of the $\chi$ and $\psi$ genes of $P$. aeruginosa, $E$. coli and $P$. putida.

\section{Acknowledgements}

The authors thank Lidia Litz and Olga Fettscher for excellent technical assistance, Dr. Claus Urbanke for help with the analytical ultracentrifuge, valuable discussions and for critically reading the manuscript, Dr. Lutz Wiehlmann for supplying the PAO1 genomic DNA and the KT2440 strain and for helpful discussions, Drs. Joachim Greipel, Karl-Peter Hopfner and Dietmar Manstein for helpful discussions, and Mathias Flüggen for performing some of the AUC runs. We thank the staff of X33 beamline at the EMBL/DESY Hamburg for help, excellent support during data collection and fruitful discussions. This work was supported by a Georg Christoph Lichtenberg Stipend provided by the Ph.D. program Infection Biology sponsored by the Ministry of Science and Culture of Lower Saxony to SEHM. Article-processing charges were funded by the program 'Open Access Publication' of the Deutsche Forschungsgemeinschaft (DFG).

\section{Author details}

'Institute for Biophysical Chemistry, Hannover Medical School, Carl-NeubergStr. 1, 30625 Hannover, Germany. ${ }^{2}$ Department of Biochemistry, Gene Center of the Ludwig-Maximilians-University Munich, Feodor-Lynen-Str. 25, D-81377 Munich, Germany. ${ }^{3}$ Center for Integrated Protein Sciences (CIPSM), Gene Center of the Ludwig-Maximilians-University Munich, Feodor-Lynen-Str. 25, D-81377 Munich, Germany. ${ }^{4}$ Munich Center for Advanced Photonics (MAP), Gene Center of the Ludwig-Maximilians-University Munich, Feodor-Lynen-Str. 25, D-81377 Munich, Germany.

\section{Authors' contributions}

Conceived and designed the experiments: SEHM, GW, UC. Performed the experiments: SEHM, GW, NN. Analyzed the data and wrote the manuscript: SEHM, GW, NN, UC. All authors read and approved the final manuscript.

Received: 24 May 2011 Accepted: 28 September 2011

Published: 28 September 2011

\section{References}

1. Sadikot RT, Blackwell TS, Christman JW, Prince AS: Pathogen-host interactions in Pseudomonas aeruginosa pneumonia. Am J Respir Crit Care Med 2005, 171(11):1209-1223.

2. Buchanan PJ, Ernst RK, Elborn JS, Schock B: Role of CFTR, Pseudomonas aeruginosa and Toll-like receptors in cystic fibrosis lung inflammation. Biochem Soc Trans 2009, 37(Pt 4):863-867.

3. Strateva T, Yordanov D: Pseudomonas aeruginosa - a phenomenon of bacterial resistance. J Med Microbiol 2009, 58(Pt 9):1133-1148.

4. Onrust R, Finkelstein J, Naktinis V, Turner J, Fang L, O'Donnell M: Assembly of a chromosomal replication machine: two DNA polymerases, a clamp loader, and sliding clamps in one holoenzyme particle. I. Organization of the clamp loader. J Biol Chem 1995, 270(22):13348-13357.

5. Scheuermann R, Tam S, Burgers PM, Lu C, Echols H: Identification of the epsilon-subunit of Escherichia coli DNA polymerase III holoenzyme as the dnaQ gene product: a fidelity subunit for DNA replication. Proc Natl Acad Sci USA 1983, 80(23):7085-7089.

6. Stukenberg PT, Studwell-Vaughan PS, O'Donnell M: Mechanism of the sliding beta-clamp of DNA polymerase III holoenzyme. J Biol Chem 1991, 266(17):11328-11334.

7. Pritchard $A E$, Dallmann $H G$, Glover BP, McHenry CS: A novel assembly mechanism for the DNA polymerase III holoenzyme DnaX complex: association of deltadelta' with $\operatorname{DnaX}(4)$ forms DnaX(3)deltadelta'. EMBO J 2000, 19(23):6536-6545.

8. Xiao H, Dong Z, O'Donnell M: DNA polymerase III accessory proteins. IV. Characterization of chi and psi. J Biol Chem 1993, 268(16):11779-11784.

9. Kelman Z, Yuzhakov A, Andjelkovic J, O'Donnell M: Devoted to the lagging strand-the subunit of DNA polymerase III holoenzyme contacts SSB to promote processive elongation and sliding clamp assembly. EMBO J 1998, 17(8):2436-2449.

10. Witte G, Urbanke C, Curth U: DNA polymerase III chi subunit ties singlestranded DNA binding protein to the bacterial replication machinery. Nucleic Acids Res 2003, 31(15):4434-4440.

11. Yuzhakov A, Kelman Z, O'Donnell M: Trading places on DNA-a three-point switch underlies primer handoff from primase to the replicative DNA polymerase. Cell 1999, 96(1):153-163.

12. Olson MW, Dallmann HG, McHenry CS: DnaX complex of Escherichia coli DNA polymerase III holoenzyme. The chi psi complex functions by increasing the affinity of tau and gamma for delta.delta' to a physiologically relevant range. J Biol Chem 1995, 270(49):29570-29577.

13. Anderson SG, Williams CR, O'Donnell ME, Bloom LB: A function for the psi subunit in loading the Escherichia coli DNA polymerase sliding clamp. J Biol Chem 2007, 282(10):7035-7045.

14. Gulbis JM, Kazmirski SL, Finkelstein J, Kelman Z, O'Donnell M, Kuriyan J: Crystal structure of the chi:psi sub-assembly of the Escherichia coli DNA polymerase clamp-loader complex. Eur J Biochem 2004, 271(2):439-449.

15. Naue N, Fedorov R, Pich A, Manstein DJ, Curth U: Site-directed mutagenesis of the chi subunit of DNA polymerase III and singlestranded DNA-binding protein of $E$. coli reveals key residues for their interaction. Nucleic Acids Res 2011, 39(4):1398-1407.

16. Simonetta KR, Kazmirski SL, Goedken ER, Cantor AJ, Kelch BA, McNally R, Seyedin SN, Makino DL, O'Donnell M, Kuriyan J: The mechanism of ATPdependent primer-template recognition by a clamp loader complex. Cell 2009, 137(4):659-671.

17. Jarvis TC, Beaudry AA, Bullard JM, Janjic N, McHenry CS: Reconstitution of a minimal DNA replicase from Pseudomonas aeruginosa and stimulation by non-cognate auxiliary factors. J Biol Chem 2005, 280(9):7890-7900.

18. Jarvis TC, Beaudry AA, Bullard JM, Ochsner U, Dallmann HG, McHenry CS: Discovery and characterization of the cryptic psi subunit of the pseudomonad DNA replicase. J Biol Chem 2005, 280(49):40465-40473.

19. Schuck P: Size-distribution analysis of macromolecules by sedimentation velocity ultracentrifugation and lamm equation modeling. Biophys $J 2000$ 78(3):1606-1619.

20. Lebowitz J, Lewis MS, Schuck P: Modern analytical ultracentrifugation in protein science: a tutorial review. Protein Sci 2002, 11(9):2067-2079.

21. Linding R, Russell RB, Neduva V, Gibson TJ: GlobPlot: Exploring protein sequences for globularity and disorder. Nucleic Acids Res 2003, 31(13):3701-3708.

22. Volkov W, Svergun Dl: Uniqueness of $a b$ initio shape determination in small-angle scattering. J Appl Cryst 2003, 36:860-864. 
23. Putnam CD, Hammel M, Hura GL, Tainer JA: X-ray solution scattering (SAXS) combined with crystallography and computation: defining accurate macromolecular structures, conformations and assemblies in solution. Q Rev Biophys 2007, 40(3):191-285.

24. Biegert A, Mayer C, Remmert M, Soding J, Lupas AN: The MPI Bioinformatics Toolkit for protein sequence analysis. Nucleic Acids Res 2006, , 34 Web Server: W335-9.

25. Sali A, Blundell TL: Comparative protein modelling by satisfaction of spatial restraints. J Mol Biol 1993, 234(3):779-815.

26. Bernado P, Mylonas E, Petoukhov MV, Blackledge M, Svergun DI: Structura characterization of flexible proteins using small-angle X-ray scattering. J Am Chem Soc 2007, 129(17):5656-5664.

27. Mertens HD, Svergun DI: Structural characterization of proteins and complexes using small-angle X-ray solution scattering. J Struct Bio/ 2010, 172(1):128-141.

28. Garcia De La Torre J, Huertas ML, Carrasco B: Calculation of hydrodynamic properties of globular proteins from their atomic-level structure. Biophys J 2000, 78(2):719-730.

29. Witte G, Fedorov R, Curth U: Biophysical analysis of Thermus aquaticus single-stranded DNA binding protein. Biophys J 2008, 94(6):2269-2279.

30. Glover BP, McHenry CS: The chi psi subunits of DNA polymerase III holoenzyme bind to single-stranded DNA-binding protein (SSB) and facilitate replication of an SSB-coated template. J Biol Chem 1998, 273(36):23476-23484.

31. Weiner $J H$, Bertsch $L L$, Kornberg $A$ : The deoxyribonucleic acid unwinding protein of Escherichia coli. Properties and functions in replication. J Biol Chem 1975, 250(6):1972-1980.

32. Genschel J, Litz L, Thole H, Roemling U, Urbanke C: Isolation, sequencing and overproduction of the single-stranded DNA binding protein from Pseudomonas aeruginosa PAO. Gene 1996, 182(1-2):137-143.

33. Curth U, Genschel J, Urbanke C, Greipel J: In vitro and in vivo function of the C-terminus of Escherichia coli single-stranded DNA binding protein. Nucleic Acids Res 1996, 24(14):2706-2711.

34. Kozlov AG, Jezewska MJ, Bujalowski W, Lohman TM: Binding specificity of Escherichia coli single-stranded DNA binding protein for the chi subunit of DNA pol III holoenzyme and PriA helicase. Biochemistry 2010, 49(17):3555-3566.

35. Molineux IJ, Pauli A, Gefter ML: Physical studies of the interaction between the Escherichia coli DNA binding protein and nucleic acids. Nucleic Acids Res 1975, 2(10):1821-1837.

36. Williams KR, Spicer EK, LoPresti MB, Guggenheimer RA, Chase JW: Limited proteolysis studies on the Escherichia coli single-stranded DNA binding protein. Evidence for a functionally homologous domain in both the Escherichia coli and T4 DNA binding proteins. J Biol Chem 1983, 258(5):3346-3355.

37. Urbanke C, Schaper A: Kinetics of binding of single-stranded DNA binding protein from Escherichia coli to single-stranded nuclei acids. Biochemistry 1990, 29(7):1744-1749.

38. Pace CN, Vajdos F, Fee L, Grimsley G, Gray T: How to measure and predict the molar absorption coefficient of a protein. Protein Sci 1995, 4(11):2411-2423.

39. Lohman TM, Overman LB: Two binding modes in Escherichia coli single strand binding protein-single stranded DNA complexes. Modulation by $\mathrm{NaCl}$ concentration. J Biol Chem 1985, 260(6):3594-3603.

40. Zabeau M, Stanley KK: Enhanced expression of cro-beta-galactosidase fusion proteins under the control of the PR promoter of bacteriophage lambda. EMBO J 1982, 1(10):1217-1224.

41. Regenhardt D, Heuer H, Heim S, Fernandez DU, Strompl C, Moore ER, Timmis KN: Pedigree and taxonomic credentials of Pseudomonas putida strain KT2440. Environ Microbiol 2002, 4(12):912-915.

42. Dam J, Velikovsky CA, Mariuzza RA, Urbanke C, Schuck P: Sedimentation velocity analysis of heterogeneous protein-protein interactions: Lamm equation modeling and sedimentation coefficient distributions $\mathrm{c}(\mathrm{s})$. Biophys J 2005, 89(1):619-634.

43. Durchschlag $\mathrm{H}$ : Specific volumes of biological macromolecules and some other molecules of biological interest. In Thermodynamic data for biochemistry and biotechnology. Edited by: Hinz H. Berlin, Heidelberg: Springer; 1986:45-128.

44. Witte G, Urbanke C, Curth U: Single-stranded DNA-binding protein of Deinococcus radiodurans: a biophysical characterization. Nucleic Acids Res 2005, 33(5):1662-1670.
45. Konarev PV, Petoukhov MV, Volkov W, Svergun DI: ATSAS 2.1, a program package for small-angle scattering data analysis. J App/ Cryst 2006, 39:277-286.

46. Wriggers W, Chacón P: Using Situs for the registration of protein structures with low-resolution bead models from X-ray solution scattering. J Appl Cryst 2001, 34:773-776.

47. Pettersen EF, Goddard TD, Huang CC, Couch GS, Greenblatt DM, Meng EC, Ferrin TE: UCSF Chimera-a visualization system for exploratory research and analysis. J Comput Chem 2004, 25(13):1605-1612.

48. DeLano WL: The PyMOL Molecular Graphics System. Version 1.2r3pre, Schrödinger, LLC. 2002.

49. Soding J: Protein homology detection by HMM-HMM comparison. Bioinformatics 2005, 21(7):951-960.

doi:10.1186/1471-2199-12-43

Cite this article as: El Houry Mignan et al:: Characterization of the $\chi \psi$ subcomplex of Pseudomonas aeruginosa DNA polymerase III. BMC Molecular Biology 2011 12:43.

\section{Submit your next manuscript to BioMed Central and take full advantage of:}

- Convenient online submission

- Thorough peer review

- No space constraints or color figure charges

- Immediate publication on acceptance

- Inclusion in PubMed, CAS, Scopus and Google Scholar

- Research which is freely available for redistribution

Submit your manuscript at www.biomedcentral.com/submit
C Biomed Central 